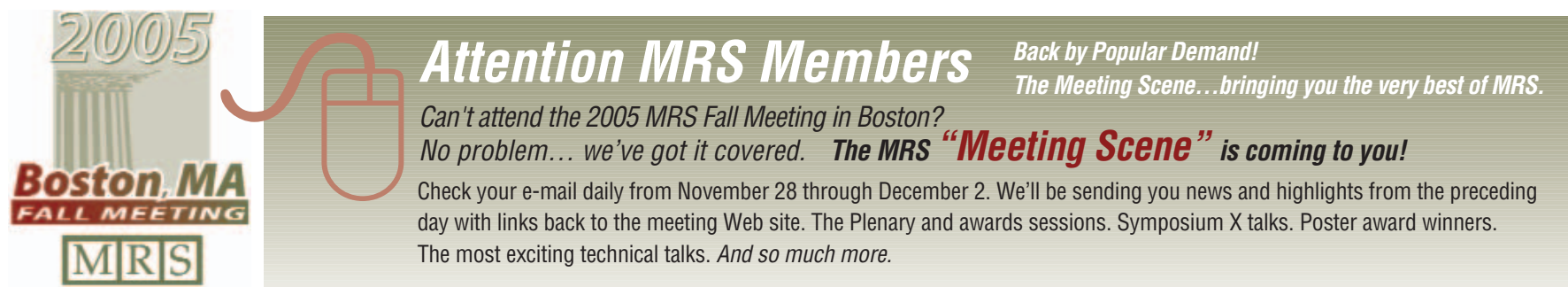

\title{
POSTERMINARIES
}

\section{The Scientific Elite and the Oppression of Pessimists}

Are you an optimist or a pessimist? An optimist, we are told, will describe a glass as being half-full, while a pessimist sees the same container as half-empty. Engineers, who pride themselves on being objective, understand that the glass is just twice as big as it needs to be. And administrators, who deal in vessels that tend to be cans of worms, are actually happier to find them half-empty.

I am concerned that there exists a pervasive bias against pessimists among the intellectual elites. The scientific elite, in particular, is overwhelmingly optimistic, and it is increasingly clear that optimism is, in fact, a prerequisite for membership in this club in the 21st century. We must ask ourselves seriously, "Is there a place for a pessimist in our Society?"

Of course, we all have a little pessimism in our personalities, and the question is one of degree and also the manner in which the pessimism manifests itself. The darkest pessimists among us have learned that they must be careful to pass as optimists in their laboratories, and they can only really let their guard down in the safety and privacy of their own homes. These are the people who know with certainty that in the Supreme Court of Fate, Murphy's Law always takes precedence over the Second Law of Thermodynamics. They know, too, that there is no point in doing the experiment, because it will not work as planned; and that the proposal will never get funded anyway. They believe that a more useful definition of the word "optimist," had it not already been claimed, would have been "a film of condensation on a lens." But despite their inner certainty that things will only get worse, they will never admit that they are pessimists. When challenged, the most that they will ever confess is being a "realist." This is indeed an oppressed minority.

Optimism is a characteristic of a researcher: How many of you have done an experiment "just to see what happens"? And how many such experiments would be done if all researchers were pessimists? There are a few classic experiments where the level of optimism displayed by the perpetrators is truly astounding, and this is perhaps the hallmark of really great experimental science. Among my favorites in this regard is the first measurement of the vacancy content of various metals by Simmons and Balluffi, allowing the determination of the vacancy formation energy: They measured the difference between the bulk thermal expansion coefficient and the variation in lattice parameter, as described in an article in MRS Bulletin (Vol. XVI, February 1991, p. 23). Imagine undertaking such an experiment when the outcome was unknown and it was not possible to know ahead of time how much precision was required in the various measurements. You can pick your own favorite candidate for the experimental Hall of Fame, and contemplate the optimism that it took to undertake it before the result was known.

\section{"How many of you have done an experiment "just to see what happens'?"}

Pessimism has its place, too. You need just the right amount of pessimism, and the sense to apply it appropriately. Analyzing your data should be done with a pessimistic skepticism, for you must know that at least your own level of skepticism will be applied in the reviewing process after you submit the work for publication. I do have a sense that an inappropriate level of pessimism is evident in the review of proposals, and this is certainly where the clash between optimists and pessimists is most critically played out. Optimistic proposers: "Imagine this..." versus the pessimistic reviewers: "It'll never work." It seems either that those funding agencies have a secret list of closet pessimists who are bent on revenge against their optimistic oppressors, or that receiving a proposal for review triggers some kind of Pavlovian pessimism response, conditioned into all of us during our days as graduate students. (Pavlov, of course, was an optimist. What kind of pessimist would do behavioral experiments with hungry dogs?)

Materials laboratories tend to be diverse environments. You can usually find more women or minorities there than in most other technical disciplines. You also find more pessimists, and this may have something to do with being a discipline at the intersection between science and engineering. Engineers have to be pessimists, after all. I want the bridge that I cross, and the plane that I ride, to be designed by confirmed pessimists: People who always take all of the worst possible circumstances into account and then multiply it by a healthy safety factor; people who look both ways before crossing a one-way street. But why is it that reviewing a proposal brings out the engineer/pessimist in us? The rumor is that physics and astronomy proposals are better reviewed (meaning more highly rated, on average) than materials proposals, and perhaps this is because the reviewers have much lower pessimism quotients, being more scientists than engineers. Nevertheless, I am assured that even the most ardently optimistic mathematician will usually turn at least a few shades more pessimistic when faced with a proposal to review. René Descartes, presumably disappointed by a lack of funding, once asked, "An optimist may see a light where there is none, but why must the pessimist always run to blow it out?"

Just as the oppressed have always found ways to exact some form of secret revenge on their oppressors, the pessimists in our midst are understandably angry and are working quietly and secretly to resist the hegemonic optimist agenda. Their resistance is growing ever more open and strident: The time has come for the optimists to relinquish the position of privilege and power that they have enjoyed for so long. The pessimists demand to be heard, and their liberation movement will soon rise up and take back the keys to the laboratories....

Um, ahh... Nah. It'll never happen.

AlEx KING 